\title{
Research on the Public Comfort Cognition of Silk Fabrics for Garment---Base on the Survey Data from Hangzhou, China
}

\author{
Xiangyang $\operatorname{Bian}^{1} \&$ Aijuan $\mathrm{Cao}^{1,2}$ \\ ${ }^{1}$ College of Fashion and Design, Donghua University, Shanghai, China \\ ${ }^{2}$ Highfashion Womenswear Institute, Hangzhou Vocational \& Technical College, Hangzhou, China \\ Correspondence: Xiangyang Bian, College of Fashion and Design, Donghua University, Shanghai, NO.1882, \\ West Yan-an Road, 200051, China. Tel: 86-21-6237-3978. E-mail: bianxy@dhu.edu.cn
}

$\begin{array}{lrr}\begin{array}{l}\text { Received: May 23, } 2018 \\ \text { doi:10.5539/ass.v14n8p107 }\end{array} & \text { Accepted: June 4, } 2018 \quad \text { Online Published: July 27, } 2018 \\ \text { URL: https://doi.org/10.5539/ass.v14n8p107 }\end{array}$

\begin{abstract}
As the traditional products with local characteristics in Hangzhou, silk has numerous excellent qualities. However, public cognition degree about the performance of silk fabrics remains unclear. In this paper, taking comfort as the entry point, the thesis retrieves seven indicators related to temperature comfort and contact comfort to develop silk fabrics comfort measurement scale based on traditional evaluation methods, and public comfort cognition of silk fabrics for garment is investigated through questionnaire. According to the results, the public have higher awareness to skin comfort and softness of silk fabrics, while have lower awareness to moisture absorption feature, heat conductivity and warmth retention property of silk fabrics; industry and experience in using exert a significant effect on their recognition, while gender, education background, occupation, and time length living in Hangzhou have no significant effect on cognition.
\end{abstract}

Keywords: silk fabric, comfort, cognition, scale, questionnaire investigation

Comfort, aesthetics and practicability constitute the three basic requirements of people on clothing, among which comfort is the most fundamental and foremost element (Yuan, Zhang \& Wu, 1987, p. 13-18). Clothing comfort is the mutually interactive effect among human body, environment and clothing, which could be manifested by the temperature comfort from the perspective of clothing fabric heat and moisture transfer performance, the contact comfort from the perspective of fabric performance, the structural comfort and movement comfort from the perspective of clothing style and human engineering, and the visual comfort from the perspective of psychology. At present, most evaluations concerning clothing comfort surround around specific sample clothing or fabrics. For instance, the research might invite the respondents to dress the clothing and make subjective assessment on their sense judgment for the clothing in physiology and psychology; or follow the objective assessment method which tests the performance indicators of fabric comfort and records the physiological parameter changes of respondents via instrument and heating manikin.

Above-mentioned assessment methods could provide practical and effective evidence for the development and improvement of functional clothing. However, in daily life, in consideration of the ever-changing clothing styles, numerous varieties and performances of silk fabrics, it is hard to use these methods in assessment. In consequence, based on the industrial features of Hangzhou, the Home of Silk, the author teases relevant assessment indicators concerning silk fabrics comfort and compiles the questionnaire to conduct research in Hangzhou region and learn Hangzhou residents' cognition to common silk fabrics comfort, with the view to offer reference to the product research, development and sales of silk clothing companies.

\section{Development of Measurement Scale}

\subsection{Retrieval of Measurement Indicators}

The comfort of fabrics could be primarily revealed by two aspects. The first one is whether clothing has cushion protection function on the hot and cold feelings of human body in case of environment temperature changes. The second one is the contact sense between clothing and skin (Zhang, Yu, \& Lu, 2005, pp. 65-69). In consequence, fabrics comfort cognition investigation should start from two aspects, namely temperature comfort and contact comfort. Temperature comfort primarily refers to the physical properties of fabrics, including moisture 
penetrability (moisture absorption and moisture liberation property), breathability, water permeability (water absorption property), warmth retention property (heat retaining property), heat conductivity, air containing, and water retaining property. Contact comfort includes the hand feelings, antistatic property, and cold-hot sensation of fabrics. To be sure, silk fabrics could bring about intense psychological comfort to people out of its prominent gloss, texture and style. However, in view of its proximity to "clothing aesthetics", this part will be not explored in the thesis.

Therefore, the author retrieves seven measurement indicators including moisture absorption property, moisture liberation property, breathability, heat conductivity, warmth retention property, antistatic property, softness, skin comfort as the measurement indicators of silk fabrics comfort.

\subsection{Verbal Description of Measurement Questions}

Moisture absorption property refers to the ability for fiber material to absorb moisture in the gaseous environment which could be measured by fiber moisture regain. The most important factor used to regulate clothing microclimate is fiber moisture absorption and moisture liberation property (Yang, 2001, p. 11). Fiber with favorable moisture absorption property could more easily absorb the sweat discharged by human body and therefore regulating body temperature, removing moisture and creating comfort to human body. The convention moisture regain of silk fiber as around $10 \%$ symbolizes favorable moisture absorption performance. The questionnaire describes that "the silk fabric has favorable moisture absorption property" here.

Warmth retention property refers to the ability for fabrics to prevent heat dissipation which could be measured by specific heat coefficient or heat conductivity coefficient. Silk fiber has maximum specific heat and minimum heat conductivity in natural coefficient. Hence, silk fabric has better warmth retention property in winter and thermal insulation and heatstroke prevention function in summer (Yuan, Zhang, \& Wu, 1987, pp. 13-18). Comparing with cotton fabrics, it has prominent advantage in warmth retention (Zhou, Zhang, \& Wei, 2014, pp. 54-57). With the porosity as high as $70 \%$, silk fiber has relatively favorable warmth retention performance. The questionnaire describes that "the silk fabric has favorable heat conductivity and warmth retention property and makes people feel warm in winter and cool in summer".

Relative to moisture absorption property, moisture liberation property refers to the ability for fiber material to emit vaporous water. Out of its excellent moisture liberation property, silk fabric has good moisture absorption, fast moisture liberation, and large water regain performance (Yuan, Zhang, \& Wu, 1987, pp. 13-18). The questionnaire describes that "the silk fabric does not stick to the body in summer due to its ideal moisture liberation property".

Permeability affects the ventilation of clothing (Ke \& Li, 2015, pp. 164-170) and refers to the performance for gas molecule to permeate into the fabrics. It is often expressed by air permeability. Fabrics structure and fiber material could affect fabrics breathability. Comparing with most fiber clothing, the questionnaire describes that "silk cloth has favorable breathability". Various parameters of real silk thermal comfort all remain at the optimal level (Li \& Jiang, 1994, pp. 44-50).

Antistatic property could be measured by mass specific resistance. Fiber with poor moisture absorption performance usually has higher mass specific resistance. Fiber friction easily produces static electricity, and forces the fabrics to absorb ash and easily turn dirty. The entanglement of fabrics and the stickiness between fabrics and skin hinder the movement of human body (Wu, 2009, p. 40). Such fabric has poor contact comfort. Silk fiber has favorable moisture absorption and antistatic performance. The questionnaire describes that "the silk fabric has excellent antistatic property".

Softness is resulted from the stiffness effect of fiber, and specifically speaking, the fitness of fiber in root. In daily life, people could measure the softness by hand feelings. Silk fiber is the finest one among all natural fibers and silk fiber fabric has delicate, smooth and comfortable tactile sense. The questionnaire describes that "the silk fabric has soft, smooth and flexible tactile sense".

Skin comfort is a relatively comprehensive concept. It not only includes the contact comfort between fabric and skin, but also covers thermal-wet comfort. Silk fiber is kind of natural protein fiber born from silkworm spinning. With PH value ranging between 6 and 6.5, silk fiber feels fine, tender and smooth like human skin. Consequently, it impresses people with tactile comfort. At the same time, in proximity to the chemical components of human skin, silk fiber contains 18 amino acid required by the human body (Yao, 2003, pp. 94-97). Out of its fine, smooth and comfortable tactile sense, silk fiber has good affinity with human skin (Yang, 2001, pp. 18-21). The questionnaire describes that "silk fabric has favorable skin affinity and comfortable tactile sense".

In combination with above measurement questions, the thesis follows Lickert five-level scale to form a cognition 
assessment scale for silk fabrics comfort (shown in Table 1).

Table 1. Cognitive Assessment for Silk Fabric Comfort

\begin{tabular}{|c|c|c|c|c|c|c|}
\hline SN & Questions & $\begin{array}{l}\text { Totally do } \\
\text { not } \\
\text { understand }\end{array}$ & $\begin{array}{l}\text { Do not } \\
\text { know too } \\
\text { much }\end{array}$ & uncertain & $\begin{array}{l}\text { Basically } \\
\text { understand }\end{array}$ & $\begin{array}{l}\text { Under } \\
\text { stand } \\
\text { well }\end{array}$ \\
\hline 1 & $\begin{array}{l}\text { Silk fabric has favorable moisture absoprtion } \\
\text { performance }\end{array}$ & 1 & 2 & 3 & 4 & 5 \\
\hline 2 & Silk fabric has favorable breathability & 1 & 2 & 3 & 4 & 5 \\
\hline 3 & Silk fabric has favorable antistatic property. & 1 & 2 & 3 & 4 & 5 \\
\hline 4 & $\begin{array}{l}\text { Silk fabric has favorable moisture liberation } \\
\text { performance and does not stick to human body } \\
\text { in summer. }\end{array}$ & 1 & 2 & 3 & 4 & 5 \\
\hline 5 & $\begin{array}{l}\text { Silk fabric has favorbale heat conductivity and } \\
\text { warmth retention performance and makes } \\
\text { people feel warm in winter and cool in summer. }\end{array}$ & 1 & 2 & 3 & 4 & 5 \\
\hline 6 & $\begin{array}{l}\text { Silk fabric has soft and smooth tactile sense and } \\
\text { great flexibility. }\end{array}$ & 1 & 2 & 3 & 4 & 5 \\
\hline 7 & $\begin{array}{l}\text { Silk fabric has favorable skin affinity and } \\
\text { comfortable skin contact. }\end{array}$ & 1 & 2 & 3 & 4 & 5 \\
\hline
\end{tabular}

\subsection{Scale Reliability Analysis}

This research adopts Cronbach internal consistency coefficient ( $\alpha$ coefficient) to analyze indicator reliability. Cronbach's $\alpha$ value as 0.7 in the range of low reliability should be denied in use. As indicated by the reliability analysis results targeted at small sample, $\alpha$ coefficient in the research data as 0.893 is obviously above 0.7 , which proves the relatively high reliability of the questionnaire in general.

\section{Research Methods and Principles}

Based on personal cognition subjective assessment method, this research firstly retrieves relevant indicators concerning silk fabrics comfort performance to develop the measurement scale and compile the questionnaire, subsequently resorts to questionnaire investigation to collect standard quantitative data and analyze the research results by way of mathematical statistics method, and eventually finds possible statistical law or phenomena in need of attention or further discussion in quantity.

\subsection{Questionnaire Design}

The questionnaire is composed of two parts. The part designs single choice structural questions from the eight aspects of respondents' demographic characteristics, including gender, age, education background, economic income, occupation type, duration in Hangzhou, industry, and silk clothing purchase or use experience. The second part designs single choice questions to inquire respondents' understanding about the description of all indicators related to silk fabrics comfort with Likert five-level scale.

\subsection{Method and Principle}

For conducting statistical analysis on the investigation results, the thesis marks respondents' cognition to all indicators of silk fabrics comfort (including "totally do not understand", "do not understand too much", "uncertain", "basically understand", "understand well") by 1,2,3,4,5 and accordingly derives the cognition point $\mathrm{S}_{\mathrm{ij}}$ of respondent $\mathrm{i}$ to every silk fabrics comfort $\mathrm{j}$ indicator, and calculates individual cognition degree $\mathrm{S}_{\mathrm{i}}$, average single item cognition degree of overall samples $\mathrm{MS}_{\mathrm{j}}$ and average cognition degree MS. Here is the formula.

$$
\begin{gathered}
\mathrm{S}_{\mathrm{i}}=\sum_{j=1}^{5} \mathrm{Sij} \\
\mathrm{MS}_{\mathrm{j}}=\frac{1}{n} \sum_{i=1}^{n} S i j \\
\mathrm{MS}=\frac{1}{n} \sum_{j=1}^{5} \quad \sum_{i=1}^{n} S i j
\end{gathered}
$$

Statistical software SPSS19.0 is applied for the input and analysis of questionnaire data (Rong, 2012, p. 271-280). Relevant data have been introduced to EXCEL2013 for drawing. 


\subsection{Sampling and Sample}

The research distributes 600 questionnaires in the shopping malls, exhibitions, airports and railway stations in Hangzhou region and recollects 508 effective questionnaire with the recovery rate of $84.67 \%$. In 508 effective questionnaire, there are 154 males and 354 females; 99 respondents aged 25 and below, 173 respondents aged 26-35, 130 respondents aged 36-45, 66 respondents aged 46-55, and 40 respondents aged above 55; 44 respondents with technical secondary education degree and senior high school education degree and below; 96 respondents with college degree, 222 respondents with bachelor's degree, and 146 respondents with master's degree and above; 132 respondents with monthly income of 3500 RMB and below, 144 respondents with monthly income of 3501-6000 RMB, 142 respondents with monthly income of 6001-10000 RMB, and 90 respondents with monthly income of 10000 RMB; 361 employees in enterprise and public institution, 68 college students; 79 freelancers and other practitioners; 187 staff in silk industry, 321 consumers; 138 respondents who have been living for less than one year in Hangzhou, 101 respondents who have been living for 1-3 years, 78 respondents who have been living for 4-10 years, and 191 respondents who have been living for over 10 years; 437 respondents who have silk clothing purchase or use experience and 71 respondents who do not have silk clothing purchase or use experience. Target audiences covered by the questionnaire could basically represent the average cognition situation of the public.

\section{Investigation Results and Analysis}

\subsection{Average Cognition to Silk Fabrics Comfort}

The investigation results of statistical analysis indicate that the mean value of public cognition of silk fabrics comfort is 4.16. In the sequence from low to high, there successively ranks moisture absorption property (3.81), heat conductivity and warmth retention property (3.91), antistatic property (4.09), breathability (4.27), softness (4.38) and skin comfort (4.53). Please refer to Fig.1 for more details. The two indicators which obtain maximum average cognition scores are skin comfort and softness, while the two indicators which obtain minimum average cognition scores are moisture absorption property, heat conductivity and warmth retention property. To some extent, it implies that respondents generally have high cognition to the external contact comfort of the "touch and tactile sense" of silk fabric but have low cognition to "perceived" internal temperature comfort.

By making a comparative study between groups in the silk industry and groups in the non-silk industry, the thesis discovers the cognition discrepancy between the two groups for all indicators. Fig. 1 indicates that for the cognition to silk fabrics comfort, the average cognition score of groups in the silk industry (4.38) is apparently higher than that of groups in the non-silk industry (4.03). Besides, the cognition score of groups in the silk industry for each measurement indicator is above that of groups in the non-silk industry. On the one hand, it means that questions in the measurement scale obtain the universal acknowledgment and high assessment from insiders. On the other hand, it means that the cognition of insiders increases the mean value. In fact, general consumers have relatively lower cognition degree (4.03). Among the 7 measurement indicators for silk fabrics comfort, the two groups have supreme cognition discrepancy in antistatic property, successively followed by moisture absorption property, heat conductivity and warmth retention property.

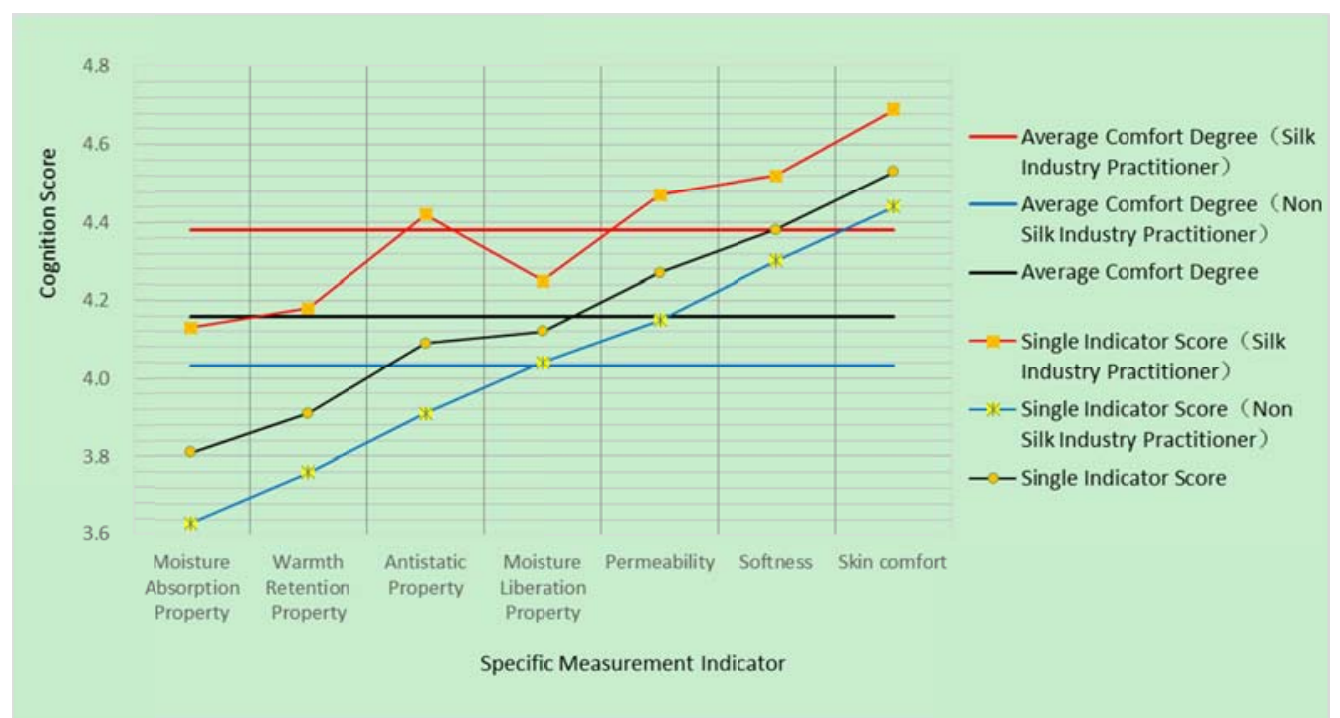

Figure 1. Investigation Results on Silk Fabrics Comfort 


\subsection{Cognition Discrepancy among Different Groups}

The thesis respectively calculates the average cognition degree of silk fabrics comfort MS of groups of respondents according to gender, age, education background, income, profession, industry, duration in Hangzhou and use experience. The supreme score respectively appears in the column of female, 46-55 age group, junior college degree, monthly income of 6001-10000 RMB, government agency or enterprise and public institution, silk industry, duration in Hangzhou for 1-3 years and groups who have silk clothing purchase and use experience (as shown in Fig 2.).

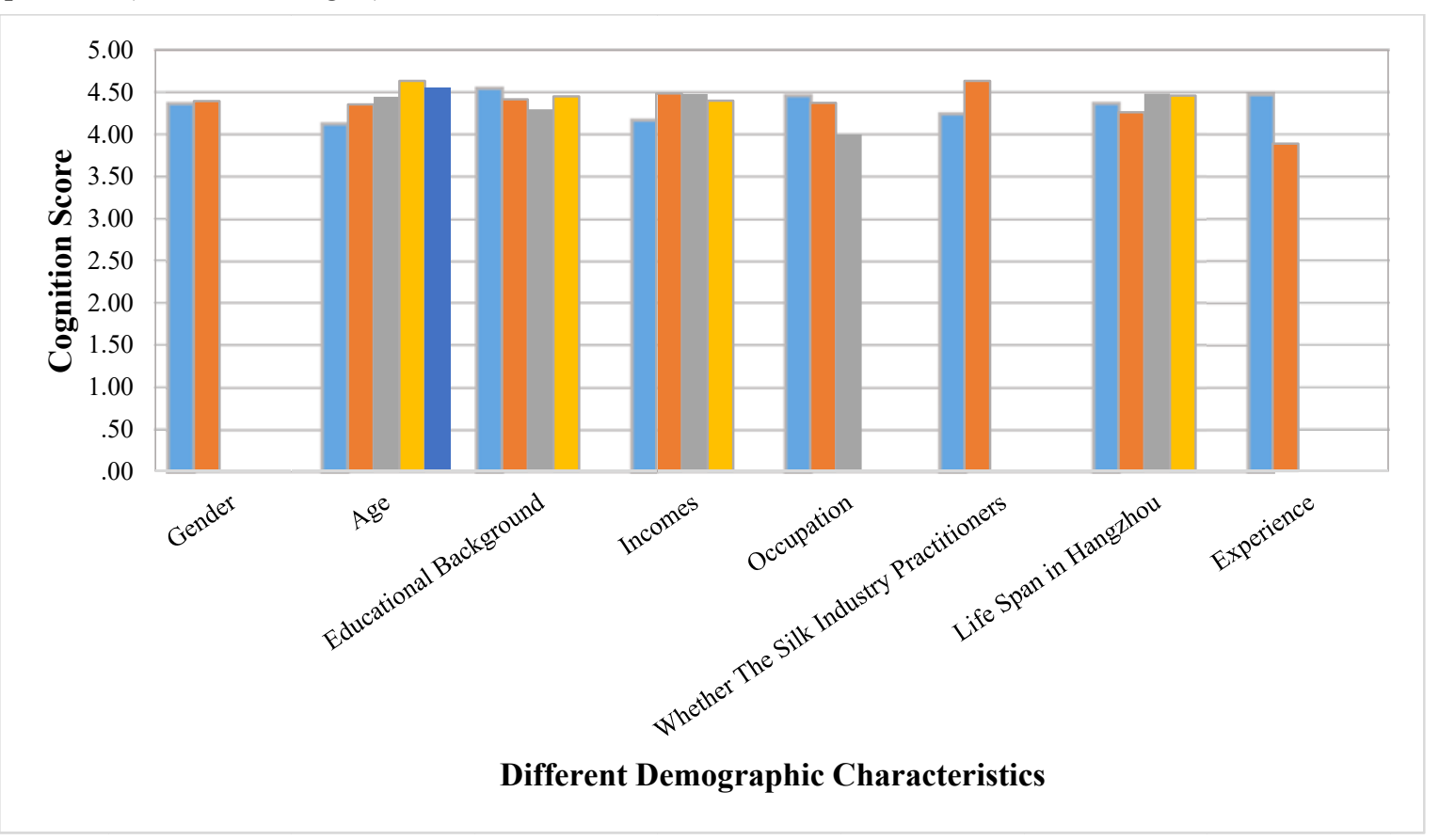

Figure 2. Cognition Differences among Different Populations

The thesis takes the individual cognition degree $\mathrm{S}_{\mathrm{i}}$ of different groups as the data sample, respectively carries out independent sample $\mathrm{T}$ test on two groups of correlation data (concerning gender, industry and use experience); $\mathrm{F}$ test ( $\mathrm{P}>0.05$, no significant discrepancy) on three or more groups of correlation data (concerning age, education background, income, occupation and duration in Hangzhou) and eventually independent sample T test on the maximum and minimum within the group.

According to $\mathrm{P}$ value, it implies that in $95 \%$ confidence interval, groups with different industries and use experience have significant comfort cognition discrepancy $(\mathrm{P}<0.05)$. The cognition level of groups in the silk industry is obviously higher than that in the non-silk industry, the cognition level of groups with silk clothing purchase and use experience is obviously higher than that of groups without purchase and use experience; there exists some discrepancy between groups with different age groups and income; the cognition level of groups aged 46-55 is obviously higher than that of groups aged 35 and below; the cognition level of groups with monthly income of 60001-10000 RMB is obviously higher than that of groups with monthly income less than 3500 RMB; there does not exist any significant discrepancy in comfort cognition between groups with different genders, education backgrounds and duration in Hangzhou ( $\mathrm{P}>0.05)$.

\section{Conclusion}

By summarizing relevant document literature related to clothing comfort, fabrics comfort and silk fabrics performance, the article designs and develops a silk fabrics comfort cognition measurement scale. The statistical analysis results for 508 data collected from questionnaire investigation for Hangzhou residents and tourists prove that the average cognition degree to silk fabrics comfort is 4.16. The cognition degree of group in the non-silk industry is simply 4.03 , which means that respondents in this group have basic understanding. Among 7 measurement indicators of comfort, the three indicators with relatively low cognition degree to group in the non-silk industry include moisture absorption property (3.63), heat conductivity and warmth retention property (3.76) and antistatic property (3.91). The cognition level of groups with silk clothing purchase and use experience (4.21) is obviously higher than that of groups without silk clothing purchase and use experience (3.85). Additionally, factors such as gender, education background and duration in Hangzhou do not have any 
significant influence on silk fabrics comfort.

Research results indicate that the cognition of ordinary people to silk fabrics comfort requires further improvement. In particular, respondents have relatively low cognition to the favorable "temperature property" of silk fabrics. It can be said that they still stay in a "stick-in-the-mud" state. For this reason, the propaganda for silk clothing could start with temperature comfort and persuade people to like silk fabrics and desire to contact and use silk clothing. As a consequence, to design and develop scarves, waistcoat, underwear and other small silk clothing products for low-income groups aged below 35 is beneficial to improve people's average cognition level and encourage silk consumption.

Due to the limitation in sample quantity and territorial scope in this research, sampling distribution is biased. While comparing the cognition of different groups, discrepancy significance within one group is affected. In view of this point, subsequent studies should choose more extensive samples for investigation. Moreover, the author adopts subjective investigation method. In the process of investigation, for learning about people's cognition to regular silk fabrics comfort, the research does not provide real clothing sample or referential fabrics for respondents. Hereby, subsequent studies should try to separate "knitted fabrics from woven fabrics and pure silk fabrics from blended yarn weaved fabrics" for in-depth exploration.

\section{Acknowledgments}

The authors would like to thank Donghua University and Hangzhou Vocational \& Technical Meanwhile, thanks for the editor and the readers of Asian Social Science.

\section{References}

Ke, Y., \& Li, J. (2015). Research and Development Trend of Clothing Ventilation. Journal of Textile Research, 36(11), 164-170. https://doi.org/10.13475/j.fzxb.20141005707

Li, D. G., \& Jiang, Y. X. (1994). Analysis on the Themal Comfort Characteristic of the Silk Fabric for Clothing. Journal of Suzhou Institute of Silk Science and Technology, 14(4), 44-50.

Rong, T. S. (2012). SPSS and Research Method (2nd ed., pp. 271-280). Dalian: Dongbei University of Finance and Economics Press.

Wu, W. W. (2009). Clothing Material (p. 40). Beijing: China Textile Press.

Yang, M. Y. (2001). Study on Comfort and Protection Property of Silk Apparel. Journal of Textile Research, 8 , 18-21. https://doi.org/10.3321/j.issn:0253-9721.2001.04.007

Yang, M. Y. (2011). Study on Comfort and Health Care Function of Silk Apparel. Hangzhou: Zhejiang University.

Yao, M. (2003). Textile Material (2nd ed., pp. 94-97). Beijing: China Textile Press.

Yuan, G. L., Wu, Z. Y., \& Zhang, H. Z.(1991). Study on the Moisture Absorption \& Heat Transfer Characteristics of Silk Fabric (I). Journal of Zhejiang Institute of Silk Science and Technology, 8(3), 24-29.

Yuan, G. L., Zhang, H. Z., \& Wu Z. Y. (1987). Comfortableness of Silk Fabric (I). Journal of Zhejiang Institute of Silk Science and Technology, 4(4), 13-18.

Zhang, P., Yu X. Z., \& Lu, X. (2005). The Wearing Comfort and New Product Development of Dress Fabric. China Textile Leader, (3), 65-69. https://doi.org/10.3969/j.issn.1003-3025.2005.03.016

Zhou, J. R., Zhang, J. M., Wei, W., et al. (2014). A Study on Performance of Real Silk Bedding Fabrics. Journal of Silk, 51(5), 54-57. https://doi.org/10.3969/j.issn.1001-7003.2014.05.011

\section{Copyrights}

Copyright for this article is retained by the author(s), with first publication rights granted to the journal.

This is an open-access article distributed under the terms and conditions of the Creative Commons Attribution license (http://creativecommons.org/licenses/by/4.0/). 